\title{
Pollution Status of Two River Estuaries in the Eastern Cape, South Africa, Based on Benthic Meiofauna Analyses
}

\author{
T. K. Gyedu-Ababio \\ Kruger National Park, P/Bag 1021 Phalaborwa 1390 South Africa \\ E-mail: thomas.gyedu-ababio@sanparks.org \\ Received March 31, 2011; revised May 2, 2011; accepted June 7, 2011
}

\begin{abstract}
The benthic meiofauna of the two river systems, the Swartkops and Gamtoos, in the Eastern Cape of South Africa has been studied extensively. Various biological indices and statistical packages were used to assess the biological status of the nematode communities in the two rivers. Nematode identification was done to the genus level. Various environmental conditions, including, concentrations of $\mathrm{Zn}, \mathrm{Mn}, \mathrm{Fe}, \mathrm{Cu}$ and $\mathrm{Pb}$, organic carbon and chlorophyll- $a$ in the sediments, were investigated in relation to the nematode density, diversity and community structure. The results of the studies indicate that higher concentrations of heavy metals had a negative impact on the nematode density, diversity and community structure. Nematode genera such as Rhabditis, Monhystera and Theristus were found to be tolerant to pollution or indicators of pollution. The Swartkops River estuary was found to be polluted more severely than the Gamtoos. It was realised that some nematode genera such as Viscosia can establish themselves along the river estuaries, irrespective of the salinity gradient. The quantitative effects of individual metals on the structure of meiobenthic communities could not be differentiated from one another. Similarly, the effects of metals and organic carbon on the structuring of the nematode communities could not be distinguished from one another. It is suggested that more studies of this kind be carried out along the coast of Africa to establish the potential indicator value of nematodes on the African continent.
\end{abstract}

Keywords: Meiofauna, Nematodes, Heavy Metals, Pollution, Community Structure, Sediment

\section{Introduction}

It has been observed that estuaries are among the most productive ecosystems in the world and are very vulnerable to anthropogenic activities. Despite this, they are subject to development pressures such as harbour development, land reclamation, urban encroachment, pollution and other anthropogenic inputs [1,2]. Many researchers have used meiofauna and nematodes in particular as indicators of pollution in different environments. They include [3-9]. A similar study [10] that applied toxicity tests on the whole nematode community from Restronguet Creek, a severely contaminated estuary, showed that nematodes are more resistant to copper than those from an adjacent, less contaminated estuary. This is a result of an increase in the abundance of $\mathrm{Cu}$ resistant species, the evolution of enhanced $\mathrm{Cu}$ tolerance in some species and the probable exclusion of more sensitive species.

[2] Observed that tolerance to copper and zinc in the benthic polychaete Nereis diversicolor is inherited. This makes it possible to use the occurrence of metal tolerant individuals to map the ecological impact of contamination by these metals.

Although there have been some studies on meiofauna in South Africa [11-14], only a few have concentrated on using nematodes as pollution indicators $[15,16]$. The community structure of the benthic meiofauna of the Swartkops estuary, with special reference to nematodes, was investigated in relation to contaminants in the estuary [15]. No studies on the meiofauna of the Gamtoos estuary have been undertaken prior to this study.

The Swartkops estuary is located in a highly industrialised area in Port Elizabeth, in the Eastern Cape Province of South Africa (Figure 1). There are different forms of agricultural activities in the upper reaches of the 
estuary as well. The Gamtoos estuary on the other hand is not industrialised. The impact on the Gamtoos is mainly from farming activities in the form of irrigation and livestock watering.

One objective of this study was to use differences in benthic meiofauna (nematode) communities as a means to contrast the "polluted" Swartkops estuary and the less impacted Gamtoos estuary. Another objective of the study was to confirm the pollution indicator status of some of the nematode genera identified by [15].

\section{Study Area}

The Swartkops River estuary is situated in Algoa Bay, about $15 \mathrm{~km}$ east of the Port Elizabeth Harbour at $33.87^{\circ}$ $\mathrm{S}$ and $25.63^{\circ} \mathrm{E}$. The estuary is $16 \mathrm{~km}$ long from its mouth to the head. The estuary is characterised by sandy beaches on the south bank and at the mouth, but the north bank rapidly gives way to many jetties and launching ramps from the residential area of Amster- damhoek. In the lower and middle reaches, mud flats and salt marshes occur, but these become less extensive as the estuary narrows towards the upper reaches. At the head of the estuary, which is marked by a concrete causeway, the substratum consists of rounded boulders and the banks are steep.

The Gamtoos River discharges into St. Francis Bay, west of Port Elizabeth and is situated at $33.88^{\circ} \mathrm{S}$ and $25.62^{\circ} \mathrm{E}$. The upper reaches of the Gamtoos River estuary are characterised by sandy beaches with shrub vegetation along their banks. Unlike the Swartkops River which is highly urbanised and industrialised, the Gamtoos River estuary flows through agricultural lands. The Gamtoos River estuary is about $21 \mathrm{~km}$ in length.

\section{Methods}

Field sampling for meiofauna and environmental factors was undertaken in the two estuaries from May 1997 to March 1998 on bi-monthly basis at neap tide in sub-tidal

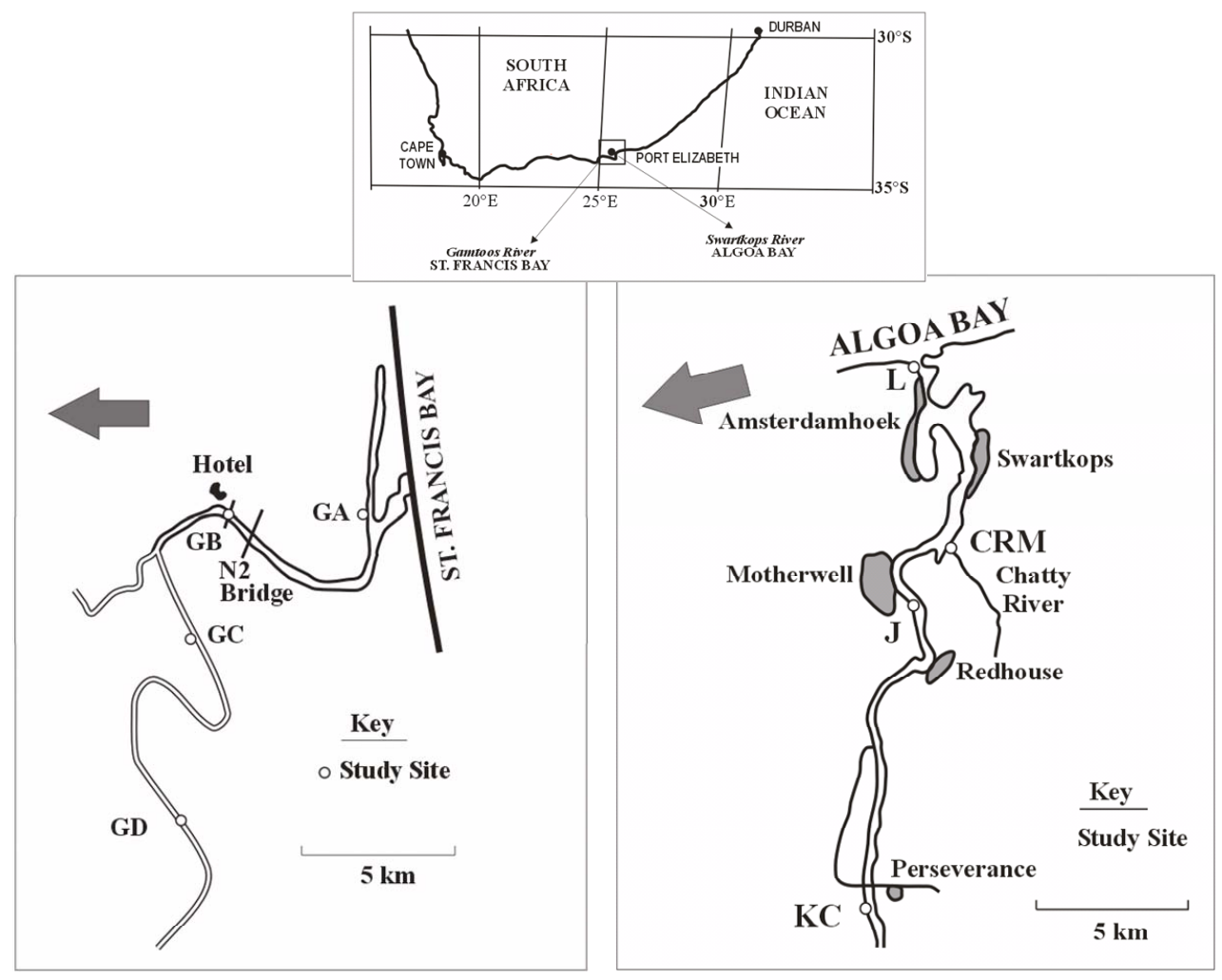

Figure 1. Map of South Africa showing the location of the Swartkops and Gamtoos River estuaries and the various sampling sites. The sites in the Swartkops River estuary are (L) at mouth of the estuary; (CRM) at the Chatty River mouth, in the middle reaches, close to the mouth of the Swartkops River estuary; $(\mathrm{J})$ at Motherwell canal in the middle reaches but nearer to the upper reaches of the estuary and (KC) Kat Canal in the fresh water reaches of the Swartkops River. Amsterdamhoek, Swartkops, Motherwell, Redhouse and Perseverance are all settlements or towns. Sites GA, GB, GC were located in the Gamtoos River estuary at the mouth, middle and upper reaches respectively. Site GD was situated above the tidal mark in the fresh water reaches of the river. The abbreviations used in the naming of the sites - G stands for Gamtoos River estuary and the $A, B, C$ and $D$ denotes which site has higher salinity beginning from the mouth. 
zones. This sampling period follows a previous study of the meiofauna community in the Swartkops River estuary conducted between May 1995 and March 1996 [15]. The sampling sites in the Swartkops River estuary were selected to include sites CRM \& KC, identified as polluted and $L$ as unpolluted [15]. The salinity ranges were 25 30; 10 - 18; 5 - 7 and 0 - 0.5 PSU units for sites L, CRM, $\mathrm{J}$ and KC respectively. The sites selected along the Gamtoos River estuary, GA, GB, GC and GD had salinity gradients and sediment particle size distributions similar to the corresponding sites selected along the Swartkops River estuary. Sampling was done using a hand held perspex corer (1 $\mathrm{m}$ long and $6.5 \mathrm{~cm}$ diameter) which penetrated to a depth of $10 \mathrm{~cm}$ as most of the meiofauna are normally found in the top $10 \mathrm{~cm}$ of the sediment [17]. Three replicate samples were taken for meiofaunal analysis at each site on each sampling trip. Samples for heavy metal analyses were taken in May 1997 and in March 1998 since the concentrations of the metals did not vary on a bi-monthly basis. Two water samples per site were taken bimonthly for chlorophyll- $a$ analysis over the sampling period.

Nematode extraction was done using a centrifugal flotation method using sucrose solution as a separating agent [18]. Nematodes were placed in 5\% formalin and counted under stereo microscope using a sorting tray as described in [15]. Nematode counts were converted to numbers per $\mathrm{m}^{2}$ and identification done using the pictorial key [19].

Heavy metal analyses were carried out, using the methods described in [15]: Shimadzu sequential plasma spectrometer (ICPS-1000II) and the calibration curve method. The chlorophyll-a concentration was determined, using the method [20]. Sediment analysis was done using the method described by [21]: A 30-g portion of the sediment from each site was washed with tap water and reweighed after drying. The dry samples were put on the topmost of a nest of sieves (with mesh size ranging from $0.002 \mu \mathrm{m}$ to $2 \mathrm{~mm}$ ) and sieved by a machine for $8 \mathrm{~min}-$ utes. The fractions of each sieve were weighed. The median grain size, sorting values, mud composition and all the other sand fractions were determined using a computer programme, SANDX - Sandsta.baj as described by [15].

\section{Statistical Analyses}

Normal distribution tests were done to assess the homogeneity or normality of samples. ANOVA and LSD tests were used to compare the nematode densities, organic content, chlorophyll- $a$, trophic and population structure at all eight sites in the two river estuaries during the sampling months. Statistical tests were made for similarities in, and difference between the sampling sites within and between the estuaries in the nematode attributes and environmental factors (salinity, pollutants and sediment particle size distribution). The nematode densities were log-transformed to reduce variability in the replicate samples. Absolute numbers were however used in relative abundance calculations. The relationship between seasons and the environmental factors on the nematode attributes was also investigated using correlation and regression analysis, (parametric and non-parametric) including Spearman-Rank Correlation and Bioenv test which is a programme within the [22] package. The Spearman-Rank Weighted Correlation/Bioenv test ranks all the environmental factors based on their influence on a particular community attribute, e.g. density or diversity.

The Maturity Index (MI) [23]: was calculated as the weighted average of the individual colonizer-persister (c-p) values.

$$
\mathrm{MI}=\Sigma v(l) f(l)
$$

Where, $v$ is the c-p value of the taxon (genus) ( $l$ ) and $f(l)$ is the frequency of the taxon in the sample. The MI is proposed here as a semi quantitative value, which indicates the condition of an ecosystem, based on the composition of the "nematode community".

Multivariate statistical techniques allow us to summarize the structure of the species associations with minimal loss of complexity [24]. A similarity matrix was constructed using the Bray - Curtis measure of similarity on 4th root transformation of the nematode attributes to further assess the similarity between the sites. The environmental factors were superimposed on the nematode attributes using the Primer programme. The relationship between the community structure and environmental parameters was analysed using the CCA (Canonical Correspondence Analysis) option from the software CANOCO [25]. It was used on the data to determine which species are associated with environmental factors that are most important in the structuring of the communities [24].

\section{Results}

\subsection{Sediment Particle-Size Distribution}

The two estuaries varied little in their particle-size distribution. There was very little or no very coarse sand (VCS) at most of the eight sites studied. Apart from site GD, all the sites showed negatively skewed distributions of the various sediment particle-size components. The 
total carbonate component (\%) of the sediment was similar in the two river estuaries although differences existed between specific sites. The \% carbonate was highest at site GA. Site L in the Swartkops River estuary has a similar sediment particle-size distribution to sites GA, GC and GD in the Gamtoos River estuary. Site GB in the Gamtoos River estuary had a similar sediment particle-size distribution to the other three sites in the Swartkops River estuary, namely CRM, J and KC (Table 1). The percentage organic carbon content of the sediment at the eight sites in the two estuaries is shown in Table 1, and indicates that the Swartkops River estuary is relatively enriched with organic matter.

\subsection{Chlorophyll-a Concentrations of Bottom Se- diments}

There were higher benthic chlorophyll- $a$ concentrations in the Swartkops River estuary, especially at site KC, compared with sites in the Gamtoos River estuary (Table 2). There was no significant difference ( $P>0.05$, ANOVA) in chlorophyll- $a$ between sites in the Swartkops estuary. There was also no significant difference $(\mathrm{P}>0.05$, ANOVA) in chlorophyll- $a$ on a temporal basis, at each of the four sites in the Swartkops River estuary. Lower chlorophyll- $a$ values were recorded in the Gamtoos River estuary. Significant differences however existed between sites both spatially and temporally in the Gamtoos estuary.

\subsection{Heavy Metals in the Sediments of the Swartkops and Gamtoos River Estuaries}

Sites GA had the lowest concentrations of the metals. Site CRM was found to be significantly different $(\mathrm{P}<$ 0.05 , ANOVA) from the other sites in terms of metal concentrations. Sites J and KC also had high concentrations of the metals $\mathrm{Cu}, \mathrm{Fe}$, and $\mathrm{Mn}$ as compared with other sites in both river estuaries (Table 3).

\subsection{Meiofauna}

The main meiofauna taxa in the Swartkops River estuary were found to be nematodes, Turbellaria, ostracods and copepods, in order of numerical importance. Copepods had a lower percentage composition amongst the meiofauna in the Swartkops River estuary compared with the Gamtoos River estuary (Table 4). Gastrotricha was not represented at all in the Swartkops River estuary in this study. A percentage dominance curve of the meiofauna taxa in the two river estuaries is shown in Figure 2. It shows that the Swartkops River estuary had a higher percentage dominance of the meiofauna taxa (very few taxa with higher numbers) as compared to the Gamtoos

Table 1. Sediment particle-size distribution at the 8 study sites in the Swartkops and Gamtoos River estuaries (May 1997March 1998).

\begin{tabular}{|c|c|c|c|c|c|c|c|c|}
\hline \multirow{3}{*}{ VARIABLE } & \multicolumn{8}{|c|}{ SITE } \\
\hline & \multicolumn{4}{|c|}{ SWARTKOPS } & \multicolumn{4}{|c|}{ GAMTOOS } \\
\hline & $L$ & $C R M$ & $J$ & $K C$ & $G A$ & $G B$ & $G C$ & $G D$ \\
\hline MEDIAN $(\mu \mathrm{m})$ & 2.64 & 2.33 & 3.1 & 2.65 & 2.19 & 3.29 & 2.57 & 2.65 \\
\hline MEAN $(\mu \mathrm{m})$ & 2.57 & 2.29 & 2.8 & 2.62 & 2.17 & 3.15 & 2.54 & 2.68 \\
\hline SORT $(\mu \mathrm{m})$ & 0.35 & 0.55 & 0.67 & 0.83 & 0.5 & 0.64 & 0.45 & 0.63 \\
\hline SKEWN $(\mu \mathrm{m})$ & -0.21 & -0.07 & -0.3 & -0.03 & -0.04 & -0.21 & -0.07 & 0.05 \\
\hline KURT $(\mu \mathrm{m})$ & 0.57 & 0.93 & 1.6 & 0.55 & 0.67 & 0.47 & 0.94 & 0.76 \\
\hline$>\mathrm{VCS}$ & 0 & 0 & 1.2 & 0 & 0 & 0 & 0 & 0 \\
\hline VCS & 0 & 1.9 & 1.6 & 0.4 & 0 & 0 & 0 & 0.1 \\
\hline CS & 0 & 0.8 & 1.9 & 0.6 & 1.2 & 0.1 & 0.4 & 2.4 \\
\hline MS & 3.4 & 11.2 & 2.6 & 6.2 & 30.9 & 1.4 & 7.8 & 10.2 \\
\hline FS & 88 & 39.8 & 13.4 & 17.4 & 60.4 & 12 & 61.4 & 56.9 \\
\hline VFS & 6.4 & 3.6 & 27.3 & 14.4 & 3.9 & 24.6 & 12.5 & 26.9 \\
\hline MUD & 2.2 & 42.6 & 51.8 & 61 & 3.6 & 62 & 18 & 3.5 \\
\hline ORGANIC & 1.07 & 3.96 & 4.33 & 5.5 & 0.48 & 1.39 & 0.65 & 0.7 \\
\hline CARBONATE & 9.68 & 4.75 & 12.6 & 5.26 & 23.15 & 4.26 & 2.22 & 1.9 \\
\hline
\end{tabular}

>VCS—more than very coarse sand; VCS—very coarse sand; CS—coarse sand; MS—Medium sand; FS—fine sand; VFS—very fine sand. 
Table 2. Chlorophyll- $a$ values $\left(\mu \mathrm{g}\right.$ per $\mathrm{m}^{2}$ ) at the sites in the two river estuaries (May 1997 to March 1998).

\begin{tabular}{cccccccccc}
\hline \multirow{2}{*}{ Month } & \multicolumn{4}{c}{ SWARTKOPS } & \multicolumn{5}{c}{ GAMTOOS } \\
\cline { 2 - 9 } & $L$ & CRM & $J$ & KC & GA & GB & GC & GD \\
\hline May '97 & 21.48 & 24.44 & 5.04 & 52.00 & 6.96 & 8.87 & 3.48 & 6.52 \\
July '97 & 11.91 & 17.42 & 8.71 & 21.39 & 3.48 & 4.52 & 1.22 & 3.04 & \\
September '97 & 12.34 & 15.71 & 47.76 & 946.02 & 59.69 & 30.83 & 8.51 & 19.62 \\
November '97 & 12.13 & 16.57 & 28.24 & 483.71 & 31.58 & 17.67 & 4.86 & 11.33 \\
January '98 & 15.24 & 19.19 & 20.51 & 120.23 & 23.37 & 14.74 & 4.40 & 9.73 \\
March '98 & 14.46 & 18.53 & 22.44 & 41.22 & 25.43 & 15.47 & 4.52 & 10.13 \\
Mean & 14.59 & 18.64 & 22.12 & 277.43 & 25.09 & 15.35 & 4.50 & 10.06 \\
Std deviation & 3.64 & 3.11 & 15.29 & 370.53 & 20.18 & 9.00 & 2.37 & 5.57 \\
Std Error & 1.49 & 1.27 & 6.24 & 151.27 & 8.24 & 3.67 & 0.97 & 2.27 \\
\hline
\end{tabular}

Table 3. Mean metal concentrations ( $\mu \mathrm{g} / \mathrm{g}$ sediment) at the sampling sites in the Swartkops and Gamtoos River esturies in May 1997 and March 1998 (SD values in brackets).

\begin{tabular}{|c|c|c|c|c|c|c|c|c|}
\hline \multirow{3}{*}{ Metals } & \multicolumn{8}{|c|}{ SITES } \\
\hline & \multicolumn{4}{|c|}{ SWARTKOPS } & \multicolumn{4}{|c|}{ GAMTOOS } \\
\hline & $L$ & $C R M$ & $J$ & KC & $G A$ & $G B$ & $G C$ & $G D$ \\
\hline $\mathrm{Cu}$ & $46(0.03)$ & $65(3.0)$ & $67(7.02)$ & 69 (8.58) & $57(0.15)$ & $65(1.41)$ & $54(0.07)$ & 55 (4.19) \\
\hline $\mathrm{Fe}$ & $1900(14.14)$ & $4500(84.85)$ & 16420 (565.69) & $16400(282.84)$ & 3520 (28.28) & 12630 (77.78) & 6850 (70.71) & $5600(141.42)$ \\
\hline Mn & $64(5.66)$ & $188(2.83)$ & $229(1.70)$ & 302 (2.83) & $161(7.07)$ & $191(1.41)$ & 104 (5.66) & $84(0.71)$ \\
\hline $\mathrm{Pb}$ & $\mathrm{BD}$ & $39(4.24)$ & $\mathrm{BD}$ & $\mathrm{BD}$ & $\mathrm{BD}$ & $\mathrm{BD}$ & $\mathrm{BD}$ & $\mathrm{BD}$ \\
\hline Sn & 3050 (14.14) & 9660 (226.27) & $1240(141.42)$ & 1910 (197.99) & $6680(183.85)$ & $190(14.14)$ & $300(21.21)$ & $820(28.28)$ \\
\hline $\mathrm{Zn}$ & $24(1.41)$ & 69 (2.83) & $72(14.14)$ & $210(0)$ & $22(1.41)$ & $39(0)$ & $30(0)$ & $43(2.12)$ \\
\hline
\end{tabular}

BD-Below detection limit

Table 4. Mean percentage composition of meiofauna in the Swartkops and Gamtoos River estuaries (May 1997-March 1998).

\begin{tabular}{|c|c|c|c|c|c|c|c|c|}
\hline \multirow{3}{*}{ MEIOFAUNA } & \multicolumn{8}{|c|}{ SAMPLING SITES } \\
\hline & \multicolumn{4}{|c|}{ SWARTKOPS } & \multicolumn{4}{|c|}{ GAMTOOS } \\
\hline & $L$ & $C R M$ & $J$ & $K C$ & $G A$ & $G B$ & $G C$ & $G D$ \\
\hline Nematodes & 82 & 41 & 31 & 61 & 62 & 23 & 44 & 41 \\
\hline Copepods & 2 & 24 & 15 & 3 & 14 & 18 & 20 & 7 \\
\hline Turbellarians & 11 & 8 & 33 & 4 & 9 & 5 & 2 & 10 \\
\hline Amphipods & 0 & 0 & 1 & 0 & 0 & 4 & 3 & 0 \\
\hline Halocarida & 0 & 2 & 1 & 1 & 5 & 3 & 1 & 4 \\
\hline Polychaetes & 0 & 0 & 1 & 0 & 0 & 16 & 0 & 5 \\
\hline Kinorhynchia & 1 & 0 & 5 & 1 & 4 & 16 & 18 & 3 \\
\hline Oligochaetes & 0 & 2 & 1 & 11 & 1 & 3 & 7 & 0 \\
\hline Insects & 0 & 4 & 2 & 1 & 3 & 3 & 0 & 5 \\
\hline Gastrotricha & 0 & 0 & 0 & 0 & 0 & 0 & 0 & 3 \\
\hline Ostracods & 4 & 19 & 10 & 18 & 2 & 9 & 5 & 22 \\
\hline Ciliophora & 0 & 0 & 0 & 0 & 0 & 0 & 0 & 0 \\
\hline Cladocera & 0 & 0 & 0 & 0 & 0 & 0 & 0 & 0 \\
\hline
\end{tabular}




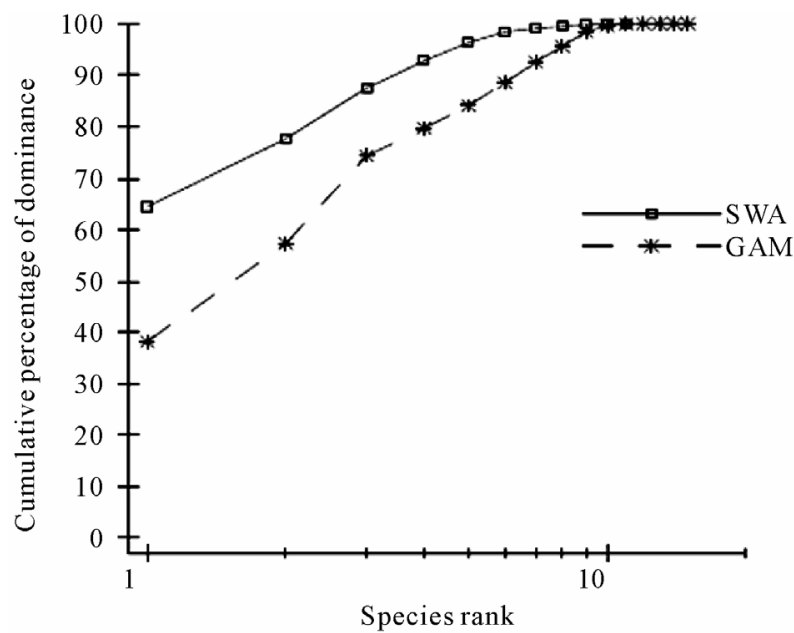

Figure 2. k-dominance curves for meiofauna in the Swartkops and Gamtoos River estuaries (May 1997-March 1998). SWA - Swartkops; GAM - Gamtoos.

River estuary. Thus, Gamtoos River estuary had a greater number of taxa (diversity) with no significant differences in their numbers.

ANOVA performed on the nematode numbers, both spatial and temporal, in the Swartkops River estuary indicated a significant difference $(\mathrm{P}<0.05)$ between sites and sampling months (Table 5). There was a significant difference ( $\mathrm{P}<0.05$, ANOVA) nematode numbers between sites in the Gamtoos estuary but not between the sampling. Site $\mathrm{L}$ had the highest total mean number $(0.8$ $\left.\times 10^{6} \mathrm{ind} / \mathrm{m}^{2}\right)$ of nematodes and site $\mathrm{J}\left(0.18 \times 10^{6} \mathrm{ind} / \mathrm{m}^{2}\right)$ the lowest in the Swartkops River estuary during the period of study. Site GD had the lowest number of nematodes $\left(0.03 \times 10^{6} \mathrm{ind} / \mathrm{m}^{2}\right)$ in the Gamtoos River estuary (Table 6). Higher nematode densities were obtained during the summer months of September and November 1997 in both Swartkops and Gamtoos River estuaries. Nematodes numbers were lowest in May 1997 in the Gamtoos River estuary but in the Swartkops, lower numbers were obtained in January and March 1998.

The genera recorded in this study are presented as Table 7. Significant difference ( $\mathrm{P}<0.05$, ANOVA) existed between the four sites and the sampling months in the numerical distribution of the nematode genera in the Swartkops River estuary over the one-year sampling period. Site L at the mouth of the Swartkops River estuary had the highest number of nematode genera, while site CRM had the least number of genera over the study period. No significant difference $(\mathrm{P}>0.05$, ANOVA) in the number of nematode genera existed either between the sampling months or between the four sites in the Gamtoos River estuary, GA, GB, GC and GD. Thus, unlike the Swartkops River estuary, distribution of the nematode

Table 5. Variation in nematode numbers on spatial and temporal basis in the Swartkops River estuary (May 1997 to March 1998)

\begin{tabular}{ccccccc}
\hline Source of Variation & SS & $d f$ & $M S$ & $F$ & P-value & F crit \\
\hline Months (temporal) & 541579.3 & 5 & 108315.9 & 5.903852 & 0.003282 & 2.801295 \\
Sites (spatial) & 280462.3 & 3 & 93487.44 & 5.095615 & 0.012499 & 3.287383 \\
Error & 275199.7 & 15 & 18346.64 & & & \\
Total & 1097241 & 23 & & & \\
\hline
\end{tabular}

Table 6. Mean monthly nematode density $\left(\mathrm{No} . / \mathrm{m}^{2}\right)$ at the study sites in the Swartkops and Gamtoos River estuaries from May 1997 to March 1998 (SD in brackets).

\begin{tabular}{|c|c|c|c|c|c|c|c|c|}
\hline \multirow{3}{*}{ Density $/ m^{2}$} & \multicolumn{8}{|c|}{ SITES } \\
\hline & \multicolumn{4}{|c|}{ SWARTKOPS } & \multicolumn{4}{|c|}{ GAMTOOS } \\
\hline & $L$ & $C R M$ & $J$ & $K C$ & $G A$ & $G B$ & $G C$ & $G D$ \\
\hline May '97 & $1.32 \times 10^{6}$ & $0.07 \times 10^{6}$ & $0.34 \times 10^{6}$ & $0.36 \times 10^{6}$ & $0.10 \times 10^{6}$ & $0.01 \times 10^{6}$ & $0.09 \times 10^{6}$ & $0.03 \times 10^{6}$ \\
\hline July '97 & $0.30 \times 10^{6}$ & $0.66 \times 10^{6}$ & $0.07 \times 10^{6}$ & $0.39 \times 10^{6}$ & $0.39 \times 10^{6}$ & $0.11 \times 10^{6}$ & $0.23 \times 10^{6}$ & $0.05 \times 10^{6}$ \\
\hline September '97 & $1.61 \times 10^{6}$ & $1.04 \times 10^{6}$ & $0.44 \times 10^{6}$ & $0.73 \times 10^{6}$ & $0.39 \times 10^{6}$ & $0.04 \times 10^{6}$ & $0.05 \times 10^{6}$ & $0.01 \times 10^{6}$ \\
\hline November ‘97 & $1.30 \times 10^{6}$ & $0.54 \times 10^{6}$ & $0.20 \times 10^{6}$ & $0.44 \times 10^{6}$ & $0.29 \times 10^{6}$ & $0.06 \times 10^{6}$ & $0.09 \times 10^{6}$ & $0.02 \times 10^{6}$ \\
\hline January ‘98 & $0.15 \times 10^{6}$ & $0.01 \times 10^{6}$ & $0.02 \times 10^{6}$ & $0.04 \times 10^{6}$ & $0.13 \times 10^{6}$ & $0.06 \times 10^{6}$ & $0.66 \times 10^{6}$ & $0.03 \times 10^{6}$ \\
\hline March ‘98 & $0.13 \times 10^{6}$ & $0.01 \times 10^{6}$ & $0.01 \times 10^{6}$ & $0.03 \times 10^{6}$ & $0.02 \times 10^{6}$ & $0.08 \times 10^{6}$ & $0.18 \times 10^{6}$ & $0.04 \times 10^{6}$ \\
\hline $\begin{array}{l}\text { Mean } \\
(\mathrm{SD})\end{array}$ & $\begin{array}{l}0.80 \times 10^{6} \\
\left(0.6 \times 10^{6}\right)\end{array}$ & $\begin{array}{c}0.39 \times 10^{6} \\
\left(0.43 \times 10^{6}\right)\end{array}$ & $\begin{array}{c}0.18 \times 10^{6} \\
\left(0.18 \times 10^{6}\right)\end{array}$ & $\begin{array}{c}0.33 \times 10^{6} \\
\left(0.26 \times 10^{6}\right)\end{array}$ & $\begin{array}{c}0.22 \times 10^{6} \\
\left(0.16 \times 10^{6}\right)\end{array}$ & $\begin{array}{c}0.06 \times 10^{6} \\
\left(0.03 \times 10^{6}\right)\end{array}$ & $\begin{array}{c}0.22 \times 10^{6} \\
\left(0.23 \times 10^{6}\right)\end{array}$ & $\begin{array}{c}0.03 \times 10^{6} \\
\left(0.01 \times 10^{6}\right)\end{array}$ \\
\hline
\end{tabular}


Table 7. Nematode numbers, feeding type and c-p values at study sites in the Swartkops and Gamtoos River estuaries (May 1997 to March 1998).

\begin{tabular}{|c|c|c|c|c|c|c|c|c|c|c|}
\hline \multirow{3}{*}{ Genus } & \multirow{3}{*}{$c-p$ value } & \multirow{3}{*}{ Feeding Type } & \multicolumn{8}{|c|}{ SITE } \\
\hline & & & \multicolumn{4}{|c|}{ SWARTKOPS } & \multicolumn{4}{|c|}{ GAMTOOS } \\
\hline & & & $L$ & $C R M$ & $J$ & $K C$ & $G A$ & $G B$ & $G C$ & $G D$ \\
\hline Adoncholaimus & 3 & $2 \mathrm{~B}$ & 8 & 0 & 0 & 0 & 78 & 7 & 12 & 0 \\
\hline Aegialoalaimus & 4 & $1 \mathrm{~A}$ & 0 & 0 & 0 & 34 & 0 & 0 & 0 & 0 \\
\hline Anoplostoma & 2 & $1 \mathrm{~B}$ & 6 & 1 & 33 & 5 & 3 & 12 & 16 & 4 \\
\hline Aponema & 3 & $2 \mathrm{~A}$ & 0 & 0 & 0 & 0 & 0 & 3 & 0 & 0 \\
\hline Axonolaimus & 2 & $1 \mathrm{~B}$ & 18 & 0 & 24 & 0 & 93 & 1 & 26 & 8 \\
\hline Butlerius & 1 & 2B & 0 & 0 & 0 & 1 & 0 & 0 & 0 & 3 \\
\hline Chromadorella & 3 & $2 \mathrm{~A}$ & 9 & 0 & 0 & 0 & 2 & 0 & 0 & 0 \\
\hline Cobbia & 3 & $1 \mathrm{~B}$ & 7 & 0 & 0 & 0 & 0 & 0 & 0 & 0 \\
\hline Comesoma & 3 & $2 \mathrm{~A}$ & 1 & 0 & 0 & 0 & 0 & 0 & 0 & 0 \\
\hline Daptonema & 2 & 1B & 18 & 0 & 41 & 0 & 8 & 4 & 190 & 26 \\
\hline Dichromadora & 3 & $2 \mathrm{~A}$ & 3 & 0 & 8 & 0 & 0 & 0 & 1 & 5 \\
\hline Dipolaimella & 2 & $1 \mathrm{~A}$ & 0 & 0 & 0 & 44 & 0 & 0 & 4 & 0 \\
\hline Dorylaimopsis & 2 & $2 \mathrm{~A}$ & 8 & 0 & 65 & 0 & 0 & 0 & 0 & 0 \\
\hline Elzalia & 2 & $1 \mathrm{~B}$ & 0 & 0 & 7 & 0 & 0 & 4 & 2 & 0 \\
\hline Ethmolaimus & 3 & $2 \mathrm{~B}$ & 0 & 0 & 0 & 0 & 0 & 4 & 3 & 5 \\
\hline Euchromadora & 3 & $2 \mathrm{~A}$ & 0 & 0 & 0 & 0 & 2 & 0 & 0 & 0 \\
\hline Gammanema & 2 & 2B & 0 & 0 & 0 & 0 & 58 & 27 & 74 & 16 \\
\hline Gonionchus & 2 & $1 \mathrm{~B}$ & 18 & 0 & 0 & 2 & 10 & 6 & 0 & 0 \\
\hline Halalaimus & 4 & $1 \mathrm{~A}$ & 0 & 0 & 7 & 47 & 7 & 0 & 0 & 0 \\
\hline Haliplectus & 2 & $1 \mathrm{~A}$ & 0 & 0 & 0 & 123 & 0 & 0 & 0 & 0 \\
\hline Karkinochromadora & 3 & $2 \mathrm{~A}$ & 0 & 0 & 0 & 3 & 0 & 0 & 4 & 0 \\
\hline Longicyatholaimus & 3 & $2 \mathrm{~A}$ & 10 & 0 & 0 & 0 & 0 & 0 & 0 & 0 \\
\hline Marylynnia & 3 & $2 \mathrm{~B}$ & 6 & 0 & 4 & 0 & 0 & 0 & 0 & 0 \\
\hline Mesodorylaimus & 4 & $2 \mathrm{~A}$ & 0 & 0 & 0 & 2 & 0 & 0 & 0 & 0 \\
\hline Mesotheristus & 2 & $1 \mathrm{~B}$ & 0 & 0 & 0 & 1 & 0 & 0 & 0 & 0 \\
\hline Metachromadora & 3 & $2 \mathrm{~A}$ & 10 & 10 & 0 & 0 & 2 & 0 & 0 & 0 \\
\hline Metacyatholaimus & 3 & $2 \mathrm{~A}$ & 7 & 0 & 0 & 1 & 0 & 0 & 0 & 0 \\
\hline Metalinhomoeus & 2 & $1 \mathrm{~B}$ & 5 & 4 & 16 & 35 & 0 & 0 & 0 & 5 \\
\hline Microlaimus & 2 & $2 \mathrm{~A}$ & 23 & 2 & 58 & 1 & 1 & 7 & 2 & 0 \\
\hline Monhystera & 2 & $1 \mathrm{~B}$ & 10 & 19 & 42 & 56 & 0 & 0 & 0 & 0 \\
\hline Mononchus & 4 & $1 \mathrm{~A}$ & 0 & 0 & 0 & 0 & 0 & 0 & 0 & 4 \\
\hline Nannolaimoides & 3 & $2 \mathrm{~A}$ & 47 & 0 & 0 & 8 & 0 & 0 & 0 & 0 \\
\hline Neochromadora & 3 & $2 \mathrm{~A}$ & 3 & 2 & 110 & 0 & 3 & 13 & 5 & 3 \\
\hline Oncholaimellus & 3 & $2 \mathrm{~B}$ & 0 & 0 & 0 & 0 & 12 & 10 & 0 & 0 \\
\hline Oncholaimus & 3 & $2 \mathrm{~B}$ & 0 & 0 & 0 & 1 & 0 & 0 & 7 & 7 \\
\hline Paracanthonchus & 2 & $2 \mathrm{~A}$ & 4 & 0 & 2 & 0 & 0 & 2 & 10 & 31 \\
\hline
\end{tabular}




\begin{tabular}{|c|c|c|c|c|c|c|c|c|c|c|}
\hline Paracomesoma & 3 & $2 \mathrm{~A}$ & 18 & 0 & 15 & 39 & 0 & 0 & 0 & 0 \\
\hline Paracyatholaimus & 2 & $2 \mathrm{~A}$ & 44 & 0 & 2 & 7 & 0 & 1 & 0 & 1 \\
\hline Paramonohystera & 2 & $1 \mathrm{~B}$ & 407 & 0 & 32 & 0 & 0 & 0 & 0 & 0 \\
\hline Parodontophora & 4 & 2B & 1 & 0 & 136 & 2 & 4 & 35 & 20 & 6 \\
\hline Perrickia & 4 & $2 \mathrm{~A}$ & 6 & 0 & 0 & 0 & 0 & 0 & 0 & 2 \\
\hline Polygastrophora & 4 & $2 \mathrm{~B}$ & 2 & 0 & 10 & 0 & 0 & 0 & 0 & 0 \\
\hline Pomponema & 3 & $2 \mathrm{~B}$ & 30 & 0 & 0 & 0 & 0 & 3 & 25 & 2 \\
\hline Praeacanthonchus & 3 & $2 \mathrm{~A}$ & 10 & 0 & 0 & 0 & 0 & 41 & 2 & 0 \\
\hline Pseudochromadora & 3 & $2 \mathrm{~A}$ & 2 & 2 & 8 & 0 & 4 & 7 & 3 & 1 \\
\hline Rhabditis & 1 & $1 \mathrm{~A}$ & 0 & 5 & 0 & 323 & 0 & 0 & 0 & 0 \\
\hline Rhynconema & 3 & $2 \mathrm{~B}$ & 4 & 0 & 0 & 0 & 0 & 0 & 0 & 0 \\
\hline Sabatieria & 2 & $1 \mathrm{~B}$ & 8 & 0 & 0 & 0 & 4 & 0 & 0 & 0 \\
\hline Scaptrella & 2 & $2 \mathrm{~B}$ & 33 & 0 & 0 & 0 & 0 & 0 & 0 & 0 \\
\hline Synodontium & 2 & $1 \mathrm{~B}$ & 0 & 0 & 0 & 0 & 0 & 0 & 1 & 0 \\
\hline Synonchium & 3 & $2 \mathrm{~B}$ & 0 & 0 & 0 & 11 & 4 & 5 & 0 & 5 \\
\hline Terschellingia & 3 & $1 \mathrm{~B}$ & 0 & 0 & 0 & 117 & 0 & 15 & 1 & 3 \\
\hline Theristus & 2 & $1 \mathrm{~B}$ & 0 & 673 & 2 & 8 & 8 & 19 & 4 & 1 \\
\hline Tripyloides & 2 & $1 \mathrm{~B}$ & 0 & 0 & 0 & 0 & 0 & 0 & 0 & 8 \\
\hline Viscosia & 3 & $2 \mathrm{~B}$ & 76 & 2 & 77 & 0 & 472 & 100 & 231 & 31 \\
\hline Xyala & 3 & 1B & 10 & 0 & 0 & 0 & 18 & 4 & 0 & 0 \\
\hline
\end{tabular}

${ }^{*} \mathrm{c}-\mathrm{p}=$ coloniser-persister.

genera in the Gamtoos River estuary appeared to be more uniform. The highest mean number of genera, 8, was recorded in the middles reaches of the Gamtoos River estuary, at sites GB and GC.

\subsection{Nematode Trophic Diversity}

All four feeding types (1A, 1B, 2A and 2B - Wieser's classification based on mouthparts) were represented in the two estuaries during the period of study. The percentage composition of the four feeding types varied from site to site in the Swartkops River estuary (Figure 3). Non-selective deposit feeders, (Type 1B) contributed a large percentage of the nematode composition in May, 50\%; July, 67\% and September, 66\% respectively. Epigrowth feeders (Type 2A) contributed a higher percentage composition than the Type 1B in November 1997, January 1998 and March 1998 but the differences were only $9 \%, 9 \%$ and 5\% respectively. Type $1 \mathrm{~B}$ was therefore the dominant feeding type in the Swartkops.

In the Gamtoos River estuary, Type $1 \mathrm{~B}$ was the dominant feeding type during four non-consecutive months. Type 1B contributed 57\%, 56.8\%, 54.2\% and $43.8 \%$ of the nematode composition for the months of July 1997 , September 1997, November 1997 and March 1998, re- spectively. In May 1997 Type 2A was the dominant feeding type comprising $53.1 \%$ of the nematode composition whilst the predators and omnivores (Type 2B) were the dominant feeding type in January 1998 in the Gamtoos estuary, with a composition of $46.4 \%$. Spatially, Type 1B was dominant in the Gamtoos as well (Figure 3). Feeding Type 1B was therefore the dominant feeding group in both estuaries, but with different degrees of dominance: Swartkops River estuary - 52\% and the Gamtoos River estuary - 41\%. The mean percentage composition of the nematode feeding types indicates that Type 2A had the second highest composition in the Swartkops River estuary comprising $27 \%$ of the total. Type 2B was the second most abundant in the Gamtoos River estuary with composition of 32\%. Selective deposit feeders (Type 1A) had the lowest representation in both the Swartkops and Gamtoos River estuaries, with a composition of $10 \%$ and $2 \%$, respectively.

\subsection{Nematode Attributes in Relation to Environmental Factors}

The four nematode feeding types from the two estuaries were pooled together and the effect of environmental factors investigated using BIOENV tests. Table 8 gives 


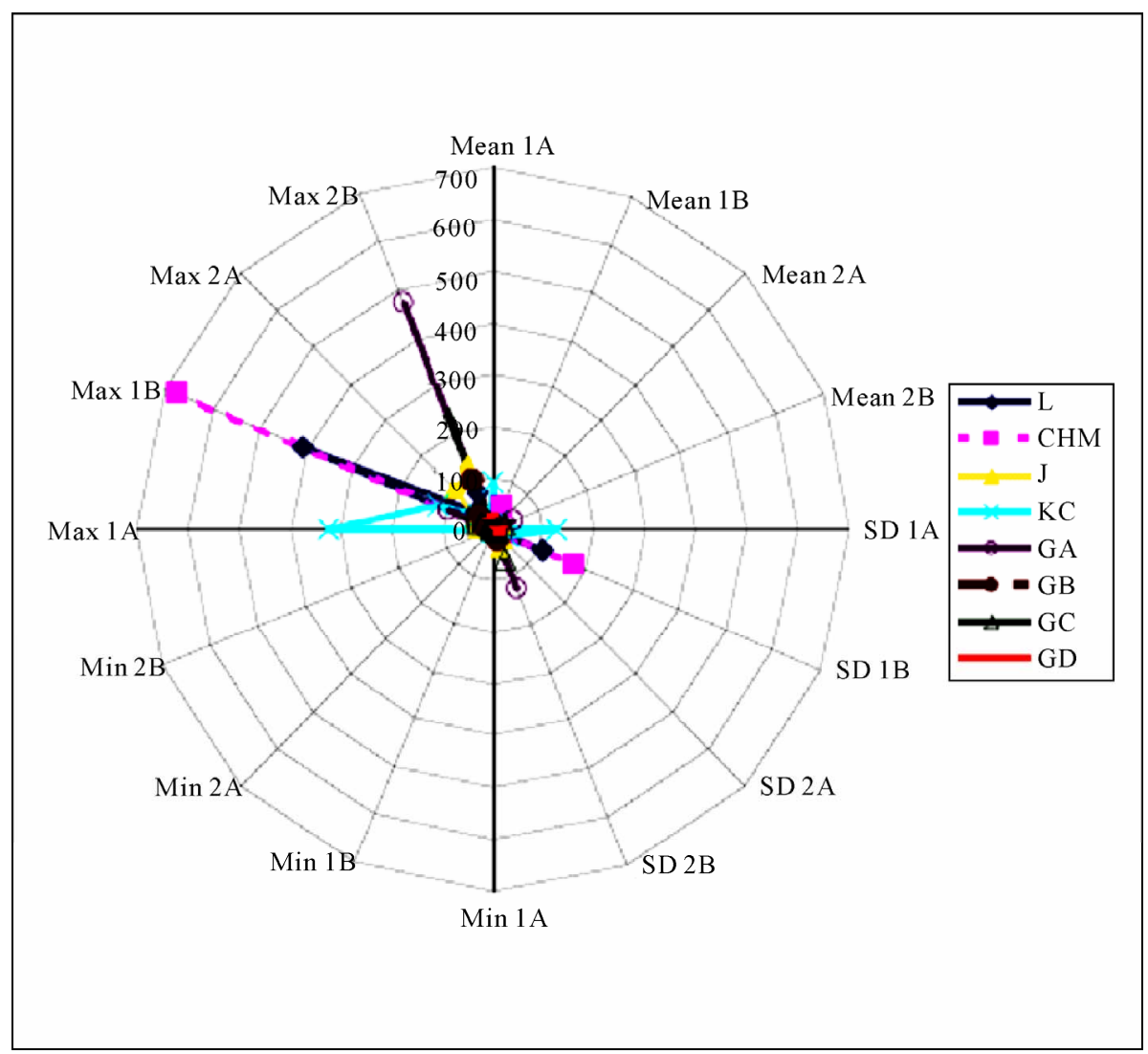

Figure 3. Graphical summary of spatial distribution of nematode feeding types in the Swartkops and Gamtoos River estuaries (May 1997-March 1998) SD—standard deviation.

Table 8. Results of Spearman's weighted correlation between nematode feeding types and environmental factors (May 1997-March 1998).

\begin{tabular}{cc}
\hline Environmental factor & $r$ \\
\hline $\mathrm{Zn}$ & 0.449 \\
$\mathrm{~Pb}$ & 0.581 \\
$\mathrm{VCS}$ & 0.586 \\
Organic carbon & 0.659 \\
Bacteria & 0.757 \\
\hline
\end{tabular}

the score of the weighted Spearman's correlation between the nematode feeding types and the environmental factors.

The metals $\mathrm{Zn}$ and $\mathrm{Pb}$, organic carbon and bacterial numbers correlated with the nematode trophic structure $(\mathrm{P}<0.05)$. All the other factors listed in Table 8 had influence on the structuring of the nematode community (the insignificant variables were not listed in Table 8).

A total of fifty-six genera were recorded in this study, from the two river estuaries. Many of the genera occurred in both estuaries, but several genera were found exclusively in either the Swartkops or the Gamtoos River estuary. Genera such as Aegialoalaimus, Cobbia, Comesoma, Dorylaimopsis, Haliplectus, Longicyatholaimus, Marylynnia, Metacyatholaimus, Monhystera, Nannolaimoides, Paracomesoma, Paramonohystera, Rhynconema, Rhabditis, Scaptrella, Mesodorylaimus and Mesotheristus occurred only in the Swartkops River. There were seven genera recorded in the Gamtoos River estuary but not in the Swartkops, namely Aponema, Ethmolaimus, Euchromadora, Gammarinema, Oncholaimellus, Tripyloides and Mononchus. Figure 4 depicts the similarities and differences in nematode communities the two river estuaries between sites.

Sites CRM and KC are at the extreme ends of the plot. This means that the two sites have nematode communities that are different from those found at the other sites based on their preference for the prevailing environmental conditions. Figure $\mathbf{4}$ also shows that the nematode community structure in the Gamtoos River estuary is very similar at all the four study sites. Whilst the Swartkops River estuary had an average number of two genera dominating the four sites, the Gamtoos River estuary had an average of three dominant genera at all four sites. Paramonohystera was dominant at site L, the mouth of the Swartkops estuary, comprising $46 \%$ of the nema- 
Nematode community structure, Stress $=0.01$

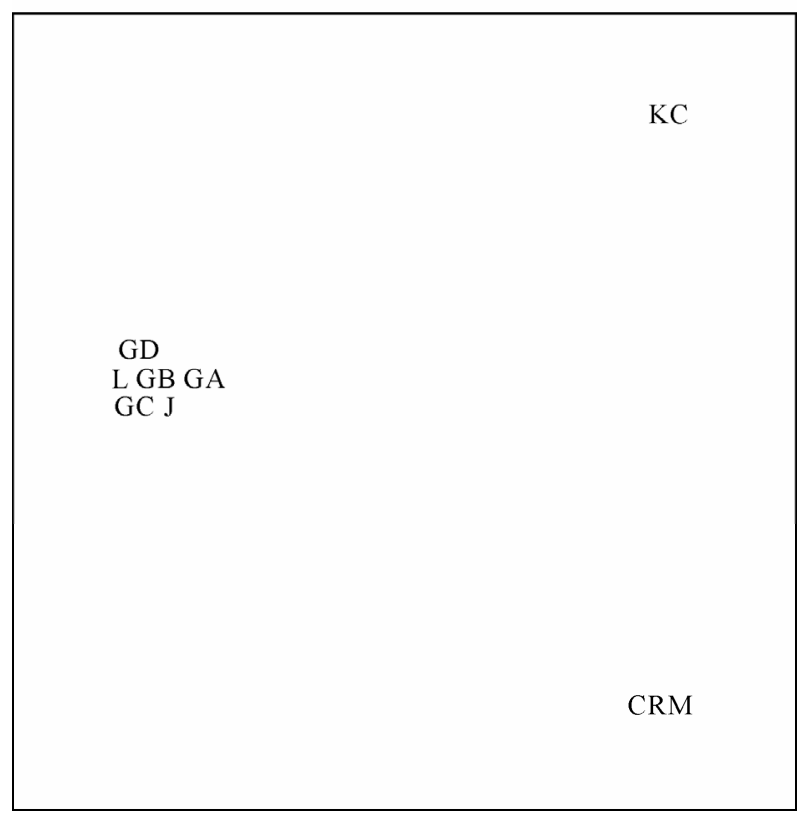

Figure 4. Non-metric MDS ordination of square-root transformed nematode taxa abundance data at study sites in the Swartkops and Gamtoos River estuaries (May 1997-March 1998).

tode community. Paradontophora, Neochromadora and Viscosia were co-dominant at site J, sharing $46.2 \%$ of the nematode community between them. Theristus was the dominant genus at site CRM, making up 93.5\% of the total numbers of the nematode community structure. Rhabditis was the most dominant (37.1\%) genus at site KC, followed by Haliplectus (14.1\%) and Terschellingia (13.4\%).

The nematode community structure in the Gamtoos River estuary was different. Viscosia was dominant in the nematode communities at all the sites in the Gamtoos. Viscosia constituted 59.5\%, 30.3\%, 35.9\% and $18.8 \%$ of total numbers at sites GA, GB, GC and GD, respectively. By contrast, Viscosia was not abundant along the sites in the Swartkops River estuary. A Canonical Correspondence Analysis (CCA) was performed to investigate the possible causes of this distribution pattern. The results of the analysis displayed in Figure 5 indicate that the nematode community structure found at sites J, L, GA, GB, GC and GD might have been caused by sediment characteristics. A greater number of the nematode communities was associated with the fine sand (FS) sediment component at these sites (Figure 6) and hence the aggregation of these sites as indicated in Figure 5.

The ability of nematode species to survive under harsh environmental conditions, e.g., metal or organic pollution has been documented [23]. According to these authors, c-p values have been assigned to various nematode genera

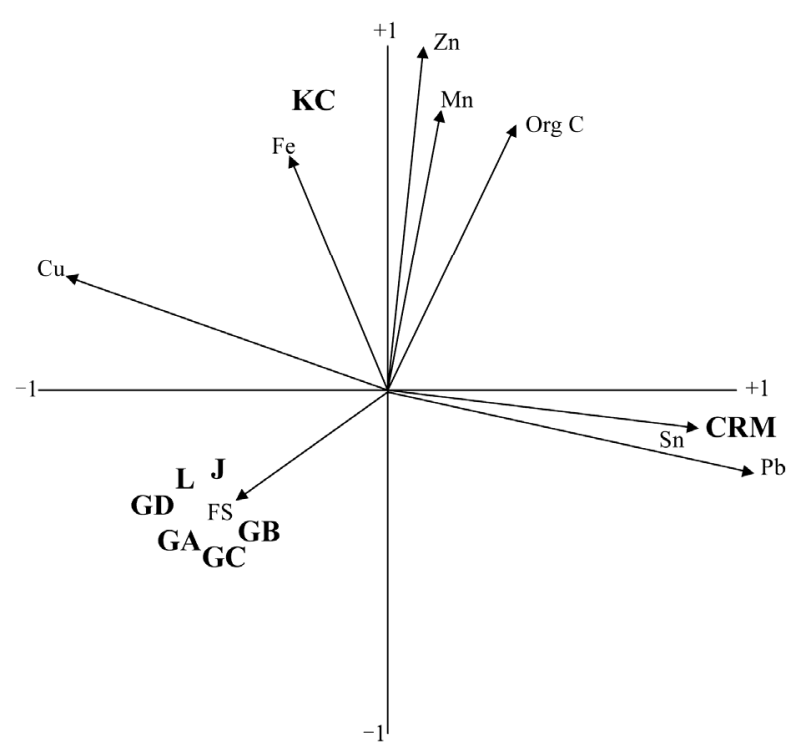

Figure 5. Comparison of study sites based on the nematode communities and environmental factors responsible for the structuring of these communities in the Swartkops and Gamtoos River estuaries (May 1997-March 1998) (FS-Fine sand, $\mathrm{Cu}-$ Copper, Fe-Iron, Zn-Zinc, Mn-Manganese, $\mathrm{Sn}$-Tin, $\mathrm{Pb}$-Lead, OrgC_-Orgnic carbon).

based on their response and survival capabilities in times of stress or disturbance. Table $\mathbf{9}$ gives the MI calculated as the weighted average of c-p values, for the nematodes at various sites in the two river estuaries. Sites that had higher metal and or organic concentrations (e.g. CRM and $\mathrm{KC}$ ) have nematode communities with lower MI values.

\section{Discussion}

Site KC had higher concentrations of $\mathrm{Cu}, \mathrm{Fe}$ and $\mathrm{Mn}$ in this study as compared to the other sites in the Swartkops River estuary. Although $\mathrm{Zn}$ is not particularly considered toxic to marine organisms [26], this study found it to have influenced the structuring of the nematode communities in the two estuaries. A similar observation was made [3] that nematode community structure appears to change in an ordered fashion with increasing metal concentration through time. There is a historic record of heavy metal concentrations in the Swartkops River estuary [15,27] and Gamtoos River estuary [28]. Sites CRM and $\mathrm{KC}$ were identified as sites with higher metal and organic carbon concentrations [15]. Table 3 gives the concentrations of the seven heavy metals analysed in the two estuaries during this study.

Several authors [29,31,32] have observed that certain nematode species including, Rhabditis and Monhystera are tolerant to hypoxic and anoxic conditions. These two genera were only found in the Swartkops River estuary at 


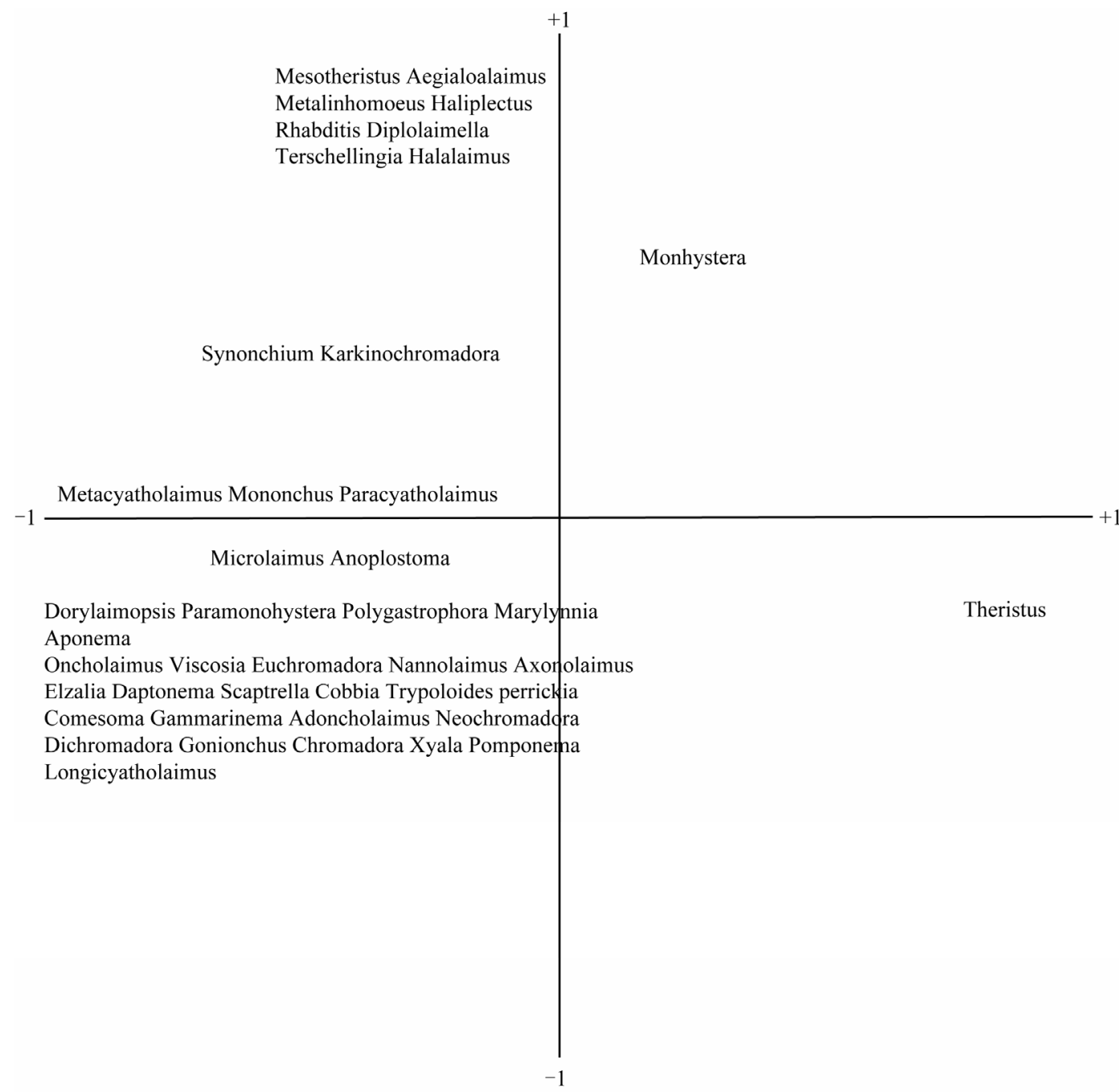

Figure 6. Nematode communities' structure in the Swartkops and Gamtoos River estuaries based on prevailing environmental conditions (May 1997-March 1998).

Table 9. Maturity Index (MI) values at study sites in the Swartkops and Gamtoos River estuaries (May 1997 to March 1998).

\begin{tabular}{|c|c|c|c|c|c|c|c|c|}
\hline \multirow{2}{*}{ Month } & \multicolumn{4}{|c|}{ SWARTKOPS } & \multicolumn{4}{|c|}{ GAMTOOS } \\
\hline & $L$ & $C R M$ & $J$ & $K C$ & $G A$ & $G B$ & $G C$ & $G D$ \\
\hline May ‘97 & 2.38 & 2.00 & 2.17 & 2.73 & 1.85 & 2.33 & 1.52 & 2.03 \\
\hline July’97 & 2.26 & 1.99 & 2.24 & 1.25 & 2.81 & 2.62 & 2.00 & 2.08 \\
\hline Sep ‘97 & 2.25 & 2.00 & 2.20 & 1.39 & 2.70 & 2.26 & 2.69 & 2.14 \\
\hline Nov ‘97 & 2.24 & 1.98 & 2.9 & 1.36 & 2.68 & 2.24 & 2.60 & 2.9 \\
\hline Jan '98 & 2.47 & 2.9 & 2.67 & 2.86 & 2.85 & 2.74 & 2.82 & 2.67 \\
\hline Mar ‘98 & 2.49 & 2.12 & 2.57 & 2.88 & 2.63 & 2.72 & 2.66 & 2.42 \\
\hline Mean & 2.35 & 2.03 & 2.33 & 2.13 & 2.67 & 2.52 & 2.43 & 2.26 \\
\hline
\end{tabular}

site KC which has high metal concentrations. As indicated earlier, there were seven nematode genera identified in the Gamtoos but not found in the Swartkops River estuary. Apart from Tripyloides and Mononchus, the other five genera were recorded in an earlier study in the Swartkops River estuary [16]. This observed change in distribution (absence of some species) might be attributed to increasing levels of pollution in the Swartkops 
River estuary.

It has been indicated that the nematode community in the Swartkops River estuary varies in composition and species abundance at specific sampling sites as a result of prevailing and variable environmental conditions along the river estuary [15]. The present study has confirmed the above observation that meiofauna density and diversity varied with respect to environmental factors such as metal concentrations in the Swartkops River estuary. The metals zinc ( $\mathrm{Zn})$, iron (Fe) and manganese (Mn) were negatively correlated with the density of nematodes in the Swartkops and Gamtoos River estuaries. A similar observation as to the correlation of nematode density with $\mathrm{Zn}, \mathrm{Pb}, \mathrm{Mn}$ and Fe [33].

One possible explanation of the results in Table 9 is that nematode genera found at sites CRM and KC might be opportunists as compared to the other sites, especially, those in the Gamtoos River estuary. The exposure of sites CRM and KC to anthropogenic activities, such as, industry, extensive agriculture and increased deposition of organic matter from the settlements along the river estuary, might also account for these species ability to "colonise" these two sites. These mentioned activities have increased the concentrations of metals and organic carbon in the Swartkops River Estuary over time. The MI values confirm the Non-metric multidimensional scaling (NMMDS) plots in Figures 5 and 6, in that, the sites with low MI are considered to be under stress from metal and organic pollution. The nematode genera associated with site KC include Monhystera, Metalinhomoeus, Rhabditis, Diplolaimella, Mesotheristus and Terschellingia. Since the metal concentrations and organic carbon concentrations were higher at this site, the genera present at this site may be tolerant to the two types of pollution. Theristus is found in organic polluted sites. It was the only genus that dominated the site CRM which is also considered as polluted (higher concentrations of $\mathrm{Pb}, \mathrm{Sn}$ and organic carbon). It is therefore difficult to pin-point which of the two, metal or organic carbon pollution, is solely responsible for the dominance of Monhystera, Metalinhomoeus, Rhabditis, Diplolaimella, Mesotheristus and Terschellingia at KC or Theristus at site CRM. The differences in the composition of benthic meiofauna communities in the two river estuaries might therefore largely depend on the synergistic effects of prevailing environmental factors. The dominant nematode feeding type $1 \mathrm{~B}$ was present at the sites considered to be stressed. This feeding type $1 \mathrm{~B}$ may adapt to stressed conditions better than the other feeding types. Apart from the fine sand (FS) component of the sediment (see Figures 5 and 6), no other environmental factors were found to have significantly influenced the structuring of the following genera; Paramonohystera, Euchro- madora, Aponema, Viscosia, Oncholaimellus, Oncholaimus, Nannolaimus, Perrickia, Praeacanthonchus, Elzalia, Polygastrophora, Cobbia, Longicyatholaimus, Scaptrella, Axonolaimus, Adoncholaimus, Dorylaimopsis, Comesoma, Rhynchonema, Xyala, Neochromadora, Ethmolaimus, Daptonema, Chromadorella.

\section{Conclusion}

This study has revealed that it is difficult to differentiate between the quantitative effects of individual metals (e.g. $\mathrm{Cu}, \mathrm{Zn}, \mathrm{Fe}, \mathrm{Pb}$ ), on the structure of nematode communities. Concentrations of the metals $(\mathrm{Cu}, \mathrm{Zn}, \mathrm{Fe}, \mathrm{Pb})$, organic carbon and chlorophyll- $a$ are higher in the sediments of the Swartkops River estuary. The sites with higher concentration of metals and organic carbon had a distinct nematode structure (e.g. site CRM with Theristus as the only genus). It is unclear if the nematode genera identified at sites CRM and KC preferred the organic carbon or the metals associated with these sites. None of the organic carbon or the individual metals can be singled out as the actual cause for the structuring of the nematode communities, as concentrations of organic carbon and the identified metals were high at these two sites. This contrasts with the observations made [34,35], who showed the effects of different metals on the structure of meiobenthic communities, could be differentiated from one another. A laboratory experiment on the meiofauna (nematodes) [16] confirmed that there is no unique way of response to specific metal contaminants by nematodes. It has been observed that responses of nematodes to lead and zinc contaminations were varied [9].

Monhystera, Metalinhomoeus, Rhabditis, Diplolaimella, Mesotheristus, Theristus and Terschellingia showed a preference for stressed conditions, including metal and organic pollution, and can therefore be considered as genera that can indicate stressed conditions. These genera were only found in the Swartkops estuary. [15] suggested that Theristus and Monhystera could be indicator species for organic and metal pollution. Since the various analyses in this study and [15], isolate Theristus, Monhystera and Rhabditis as species that prefer or can colonise polluted sites, it can be implied that nematodes can actually be used as organism that can provide an indication of sediment pollution in the coastal rivers of the Eastern Cape of South Africa. The different analyses performed in this study also confirm that the sites in the Swartkops River estuary are more polluted than those in the Gamtoos River estuary. It is suggested that more studies of this kind be carried out along the coast of Africa and globally to establish the potential indicator value of nematodes. 


\section{Acknowledgements}

I am grateful to the Zoology Department of the University of Port Elizabeth and Rand Water Analytical Services (both in South Africa), for the use of their laboratory facilities during the study period. I also thank Dan Baird (South Africa) and Tom Bongers (Dept. of Nematology, University of Wagahegen, Netherlands) for their inputs, Ann Vanreusel (Ghent, Belgium) and Aldo Zulini (Italy) for their help during the identification of some of the nematode species.

\section{References}

[1] P. Morant and N. Quinn, "Influence of Man and Management of South African Estuaries,” In: B. R. Allanson and D. Baird, Eds., Estuaries of South Africa, Cambridge University Press, Cambridge, 1999, pp. 289-320.

[2] A. Grant, J. G. Hateley and N. V. Jones, "Mapping the Ecological Impact of Heavy Metals on the Estuarine Polychaete Nereis Diversicolor Using Inherited Metal Tolerance," Marine Pollution Bulletin, Vol. 20, No. 5, 1989, pp. 235-238. doi:10.1016/0025-326X(89)90438-4

[3] P. J. Sommerfield, M. J. Gee and R. M. Warwick, "Benthic Community Structure in Relation to an Instantaneous Discharge of Waste Water from a Tin Mine," Marine Pollution Bulletin, Vol. 28, No. 6, 1994, pp. 363-369. doi:10.1016/0025-326X(94)90273-9

[4] S. Gascón, D. Boix, J. Sala and X. D. Quintana, "Nematode Assemblages and Their Responses to Disturbances: A Case Study from the Empordà Wetlands (Northeastern Iberian Peninsula)," Journal of the North American Benthological Society, Vol. 25, No. 3, 2006, pp. 643-655. doi:10.1899/0887-3593(2006)25[643:NAATRT]2.0.CO;2

[5] E. Abebe, I. Andrássy and W. Traunspurger, "Fresh Water Nematodes-Taxonomy and Assemblages," Google Books.co.za., 2006.

[6] N. Smol, K. A. Willems, J. C. R. Govaere and A. J. J. Sandee, "Composition, Distribution, Biomass of Meiobenthos in the Oosterschelde Estuary (SW Netherlands)," Hydrobiologia, Vol. 282-283, No. 1, 1994, pp. 197-217. doi:10.1007/BF00024631

[7] F. Boufahja, A. Hedfi, J. Amorri, P. Aïssa, H. Beyrem and E. Mahmoudi, "An Assessment of the Impact of Chromium-Amended Sediment on a Marine Nematode Assemblage Using Microcosm Bioassays," Biological Trace Element Research, Vol. 142, No. 2, 2010, pp. 242-255.

[8] H. Beyrem, E. Mahmoudi, N. Essid, A. Hedfi, F. Boufahja and P. Aissa, "Individual and Combined Effects of Cadmium and Diesel on a Nematode Community in a Laboratory Microcosm Experiment," Ecotoxicology and Environmental Safety, Vol. 68, No. 3, 2007, pp. 412-418. doi:10.1016/j.ecoenv.2006.12.007

[9] E. Mahmoudi, N. Essid, H. Beyrem, A. Hedfi, F. Bou- fahja, P. Aissa and P. Vitiello, "Mussel-Farming Effects on Mediterranean Benthic Nematode Communities," Nematology, Vol. 10, No. 3, 2008, pp. 323-333. doi:10.1163/156854108783900285

[10] N. R. Millward and A. Grant, "Assessing the Impact of Copper on Nematode Communities from a Chronically Metal-Enriched Estuary Using Pollution-Induced Community Tolerance," Marine Pollution Bulletin, Vol. 30, No. 11, 1995, pp. 701-706. doi:10.1016/0025-326X(95)00053-P

[11] A. McLachlan, "Studies on the Psammolittoral Meiofauna of Algoa Bay. South Africa. II. The Distribution, Composition and Biomass of the Meiofauna and Macrofauna,” Zoology African, Vol. 12, 1977, pp. 33-60.

[12] L. E. McGwynne, A. McLachlan and J. P. Furstenberg, "Wrack Breakdown on Sandy Beaches: Its Impact on Interstitial Meiofauna,” Marine Environmental Research, Vol. 25, No. 3, 1988, pp. 213-232. doi:10.1016/0141-1136(88)90004-9

[13] J. P. Furstenberg and M. Vincx, "The New Chromadoropsis Species. (Nematoda, Desmoridae) from Southern Africa and the North Sea," South African Journal of Zoology, Vol. 23, No. 3, 1988, pp. 215-223.

[14] J. P. Furstenberg and M. Vincx, "Two New Species of the Family Microlaimidae (Nematoda: Order Chromadorida) from South Africa," Cahiers de Biologie Marine, Vol. 33, 1992, pp. 245-251.

[15] T. K. Gyedu-Ababio, J. P. Furstenberg, D. Baird and A. Vanreusel, "Nematodes as Indicators of Pollution: A Case Study from the Swartkops River Estuary, South Africa,” Hydrobiologia, Vol. 397, 1999, pp. 155-169. doi:10.1023/A:1003617825985

[16] T. K. Gyedu-Ababio and D. Baird, "Response of Meiofauna \& Nematodes to Increased Levels of Contamination in a Laboratory Experiment," Ecotoxicology and Environmental Safety, Vol. 63, No. 3, 2006, pp. 443-450. doi:10.1016/j.ecoenv.2005.01.010

[17] C. Heip, M. Vincx and G. Vranken, "The Ecology of Marine Nematodes,” Oceanogr. Mar. Biol. Ann. Rev, Vol. 23, 1985, pp. 399-489.

[18] R. T. Lackey and B. E. May, "Use of Sugar Flotation and Dye to Sort Benthic Samples from Marine and Limnic Sediments," Netherlands Journal of Sea Research, Vol. 7, 1971, pp. 233-243

[19] H. M. Platt and R. M. Warwick, "Free Living Marine Nematodes, Part II: British Chromadorids,” Cambridge University Press, Cambridge, 1988.

[20] R. Mantoura and C. Llewellyn, “The Rapid Determination of Algal Chlorophyll and Carotenoid Pigments and Their Breakdown Products in Natural Waters by Reverse-Phase High-Liquid Chromotography,” Analytica Chimica Acta, Vol. 151, 1983, pp. 297-314. doi:10.1016/S0003-2670(00)80092-6

[21] S. Parker, "Determination of Soil Organic Content," In: R. E. Carver, Ed., Procedures in Sediment Petrology, John Willey \& Sons, New York, 1983, pp. 389-401.

[22] B. Curtis, "PRIMER, Plymouth Routine in Marine Envi- 
ronmental Research. Non-Metric Multidimensional Scaling," 1957.

[23] T. Bongers, R. Alkemade and G. W. Yeates, "Interpretation of Disturbance-Induced Maturity Decrease in Marine Nematode Assemblages by Means of the Maturity Index," Marine Ecology Progress Series, Vol. 76, 1991, pp. 135-142. doi:10.3354/meps076135

[24] J. Mees and O. Hamerlyncl, "Introduction to Descriptive Multivariate Statistics,” Tutorial Handout, Marine Biology Section of the University of Gent, 1996, p. 18.

[25] C. J. F. Ter Braak, “CANOCO-FORTRAN Program for Canonical Community Ordination by (Partial) Detrended (Canonical) Correspondence Analysis and Redundancy Analysis,” TNO Institute of Applied Computer Science, Statistical Department, Wageningen, 1987.

[26] G. W. Bryan and W. J. Langston, "Bioavailability, Accumulation and Effects of Heavy Metals in Sediments with Special Reference to UK Estuaries: A Review," Environmental Pollution, Vol. 76, No. 2, 1999, pp. 89-131. doi:10.1016/0269-7491(92)90099-V

[27] R. J. Watling and H. R. Watling, "Metal Surveys in South African Estuaries. II. Gamtoos River. Report II. Zoology Department,” University of Port Elizabeth, Port Elizabeth, 1982.

[28] R. J. Watling and H. R. Watling, "Metal Surveys in South African Estuaries. I. Swartkops River,” Water SA, Vol. 8, 1988, pp. 26-35.

[29] T. M. Fenchel and R. J. Riedel, "The Sulphide System: A New Biotic Community underneath the Oxidised Layer of Marine Sand Bottoms,” Marine Biology, Vol. 7, No. 3,
1970, pp. 255-268. doi:10.1007/BF00367496

[30] J. A. Ott, "Determination of Fauna Boundaries of Nematodes in an Intertidal Sand Flat," Internationale Revue der gesamten Hydrobiologie und Hydrographie, Vol. 57, No. 4, 1972, pp. 645-663. doi:10.1002/iroh.19720570413

[31] J. A. Ott and F. Schiemer, "Respiration and Anaerobiosis of Free Living Nematodes,” Oecologia, Vol. 2, 1973, pp. 251-291.

[32] J. A. Ott and R. Novak, "Living at an Interface: Meiofauna at the Oxygen/Sulfide Boundary of Marine Sediments,” In: J. S. Ryland and P. A. Tyler, Eds., Reproduction, Genetics and Distribution of Marine Organisms, Olsen \& Olsen, Fredensborg, 1989, pp. 415-422.

[33] N. Smol, K. A. Willems, J. C. R. Govaere and A. J. J. Sandee, "Composition, Distribution, Biomass of Meiobenthos in the Oosterschelde Estuary (SW Netherlands)," Hydrobiologia, Vol. 282-283, No. 1, 1994, pp. 197-217. doi:10.1007/BF00024631

[34] M. C. Austen, A. J. McEvoy and R. M. Warwick, "The Specificity of Meiobenthic Community Response to Different Pollutants: Results from Microcosm Experiments," Marine Pollution Bulletin, Vol. 28, No. 9, 1994, pp. 557563. doi:10.1016/0025-326X(94)90075-2

[35] M.C. Austen and P.J. Sommerfield, "A community level sediment bioassay applied to an estuarine heavy metal gradient," Marine Environmental Research, Vol. 43, No. 4, 1997, pp. 315-328. doi:10.1016/S0141-1136(96)00094-3 